\title{
Causes of Breakage and Disruption in a Homogeniser
}

\author{
A. Clarke, T. Prescott, A. Khan and A.G.Olabi* \\ Dublin City University, School of Mechanical and Manufacturing Engineering, Collins Avenue, \\ Dublin 9, Ireland.
}

*Corresponding author: abdul.olabi@dcu.ie

\begin{abstract}
:
Many authors have written in the past regarding the exact causes of breakage and disruption in a high pressure homogeniser, but there has been little agreement. This paper investigates some of the most likely causes of the rupture of the walls of unicellular organisms and offers suggestions obtained from various papers and work carried out.
\end{abstract}

Keywords: FEM, Fluid Dynamic, Homogeniser, Cell rupture, unicellular organisms, renewable Energy, Bio-Gas

\section{Introduction}

The high pressure homogeniser is a machine used for emulsions and suspensions to mix, disperse, and reduce the sizes of the droplets or particles of the disperse phase. It is used primarily to reduce the sizes of milk fat globules in the dairy industry. Thus, with reduced globule sizes, dairy products such as milk have a better appearance and a longer shelf life. Homogenisers are also used in the biotechnology industry to obtain yields of intracellular components. The homogeniser that will be specifically covered for this paper is the APV-Gaulin HPH (High Pressure Homogeniser). Other homogenisers include the Stansted HPH, Hielscher Ultrasonic Homogeniser and Avestin Microfluid $^{\mathrm{TM}}$.

The homogenizing valve of the homogeniser consists of 3 main regions. These will be referred as the inlet region (also referred to as the entrance region), the gap and the exit region (also called the impact region or the impingement zone). These 3 regions are labelled in figure 1.

The homogeniser functions as follows:

1. Before the gap region, a pump causes the pressure to build up to an unusually high value. A pressure pump powered by pistons typically provides this pressure. Most homogenisers today can exceed values of $150 \mathrm{MPa}$.

2. The mixture flows through a constricted passageway called the gap region. The width of this gap is adjustable by the user which allows the operating pressure to be changed. In the gap region, the fluid velocity reaches its maximum.

3. The fluid leaves the gap region and enters the exit region flowing in the direction of the impact ring. After passing through this region, the fluid leaves through the outlet. This fluid can be re-circulated for multiple passes or can be diverted off to a downstream operation. 
The concepts presented are based on the example of breaking the walls of yeast cells which are commonly found to be between 5 and 10 microns in size. However, it is expected that the principles covered should also apply to other unicellular micro-organisms of different sizes, which occur, for instance, in waste activated sludge which is illustrated in Figure 2. This is because the mechanisms of fracture are expected. Since the original function of the homogeniser was breaking up milk fat globules, there is sometimes a connection between the suggestion put forward for breaking up globules in milk, and the rupture of the walls of cells. As a result some misconceptions may have arisen. This paper aims to clear up some of the misinterpretations of ideas about emulsion breakage and cell breakage. It was also intended that the hydrodynamic phenomena that are most probably involved in the rupture of microbial cell walls in a homogeniser would be identified.

The hypothesis given in this paper are supported by simulations and experiments performed on an APV-Gaulin HPH (High Pressure Homogeniser) located at Dublin City University (DCU). Two different sets of Computational Fluid Dynamics analysis were carried out. Firstly, pressure velocity and flow fields analyses through the homogeniser were carried out; the geometries of the homogeniser and subsequent prototype changes were generated using Gambit 2.3 and pressure, velocity and flow fields were evaluated and analysed using Fluent 6.3. The initial homogeniser model was replicated from the original experimental homogeniser at DCU. And the different geometries used in other literature were also analysed. Similar CFD analysis have been carried out by $[9,20]$ Single phase and multiphase (cavitational models) have been included for water flow through the homogeniser and to predict a cell particle / buffer solution suspension. The hypothesis used by other authors can be seen in various publications referred by this paper.

Secondly, the shearing stresses on a microbe while travelling within the homogeniser were evaluated; the model was estimated by means of a stationary microbe model. Shear forces on microbes were analysed for various positions along the streamline of flow within the homogeniser and compared.

\section{Breakage and disruption theories}

Many different suggestions about the mechanisms causing cell wall rupture have been made, as can be seen in table 1 .

Table 1: Suggestions of breakage and disruption overview

\begin{tabular}{|l|l|}
\hline Breakage Suggestion & Reference(s) \\
\hline High pressure gradient & $\begin{array}{l}{[1],[2],[3],[4],[5],[6],} \\
{[7],[8],[9],[10] .}\end{array}$ \\
\hline Turbulence & {$[3],[4],[11],[6]$.} \\
\hline Cavitation & $\begin{array}{l}{[1],[6],[12],[7],[13],} \\
{[14],[7] .}\end{array}$ \\
\hline Process scale & {$[15],[8],[16]$.} \\
\hline Wall impact / impingement & {$[15],[15],[17],[9],[10]$.} \\
\hline Channel shear stress & {$[17],[9],[10]$.} \\
\hline Others (number of passes) & {$[8]$.} \\
\hline Others (separation) & {$[18]$.} \\
\hline
\end{tabular}


Often the ideas have been expressed without sufficient detail to allow the reader to understand them fully, and to form a judgement on their likelihood. In the following sections, descriptions of different theories of cell disruption mechanisms are provided.

\subsection{High Pressure Gradients / rapid decompression}

A hypothesis introduced by Brookman [2] sought to explain the mechanism of cell rupture in terms of the rapid release of pressure as cells pass through the high-pressure homogeniser. Computational fluid dynamics can be used to estimate the static pressure for a given streamline of the flow. Figure 3 shows this pressure drop for the model used in the laboratory in Dublin City University. These results were obtained by estimating the static pressure at fixed points along the streamline of a single cell passing through the homogeniser. It is worth noting that the zero pressure at the end of the streamline is artificially created by the pressure outlet boundary condition in the CFD model.

The pressure begins at a high value (in this case $4.1 \mathrm{MPa}$ ) and remains high until the flow enters the gap region. In this region the pressure then falls very quickly to a value which is less than 0.1 $\mathrm{MPa}$. The whole of the flow follows the same pattern up to this point. However variations in pressure are not experienced by all of the liquid in the exit regions of the equipment. Depending on the exact streamline being followed, in this exit region there are sections containing large vortices and the flow becomes very turbulent. At the centres of these vortices the pressure remains low, but away from these vortices the flow may be quite slow, and the pressure may build up. The pattern that is followed in this exit section is quite variable, and for some streamlines the pressure may build up, and for other streamlines there may be almost no rise in pressure at all. Similarly dramatic pressure gradients can be seen in Kleinig and Middelberg's paper of 1996 in figures 4(a) and 3(b).

It is possible that Brookman [2] assumed that the cells become deformed under the intense pressure, becoming slightly smaller. Then, when the pressure is suddenly released, the cells expand. If the rate of decompression is very high, the consequent expansion may be so fast that a momentum of expansion is developed, and when the release of pressure comes to an abrupt end, the expansion might continue with an "overshoot" effect, resulting in high tensile stresses being generated in the cell wall momentarily. If this were to be sufficiently violent, cell walls could rupture as a consequence.

The figure showing pressures against distance travelled (Figure 3) gives some indication of the speed of decompression. However, the slope of the graph gives the rate of pressure decrease per unit distance. The speed of decompression is more correctly understood to be the rate of pressure decrease per unit time. To arrive at this rate, the slope of the graph must be multiplied by the velocity of the fluid at the same point. The slope of the graph in Figure 3 was calculated to be $22,400 \mathrm{~Pa} / \mathrm{m}$ ([3.8e6-1.61 e6]/[0.06-0.0061]). As the liquid passes through the gap, this velocity is very high, particularly at the beginning of the gap. At the start of the gap, the velocity is at 74 $\mathrm{m} / \mathrm{s}$. Thus the rate of decompression at the start of the gap is equal to $1657600 \mathrm{~Pa} / \mathrm{s}$ (equals 1.6 $\mathrm{MPa} / \mathrm{s}$ ). Results as displayed in figure 3 and 4 show that the rate of decompression slows down as the pressure reaches atmospheric. Therefore there should be little chance of a momentum building up causing an overshoot effect so that the cell wall could be placed in tension. 
Since Brookman introduced these ideas, further experimentation has been carried out and various conclusions about these ideas can now be drawn. Firstly, it is now known that the contents of cells have similar compressibility properties to water. Therefore deformation under intense pressure is almost negligible.

Secondly the damaging effects of decompression can be shown to be much greater when dissolved gases are present. It is now understood that any damage to cell walls, which occurs during decompression, is most likely to be due to the formation of gas bubbles inside the cell walls. This in turn causes tensile stresses along the cell wall and eventually causes rupture. In order to enhance this effect, soluble gases need to be pumped into the fluid at high pressure so that they dissolve in large quantities. Then, when the pressure is released bubbles of the gas are produced and some of these may form within the cell walls. Indeed, it is also reported that the amount of damage is greatest when the suspension has been maintained at the high pressure for a long time, typically over one hour. This allows time for the dissolved gas to migrate by diffusion throughout the suspension including inside the cells. Such effects are most unlikely to occur in high-pressure homogenisers when operated normally. This is because firstly, the high pressure is generated by compressing the liquid, not a gas, and secondly the length of time the liquid remains at the high pressure is very short being less than a few seconds.

Another experimental approach [19] has investigated the sterilisation of foods by subjecting the food products to high pressures. It is found to be true that high pressures have this effect, presumably by damaging the spores of various cells. However this seems to depend on the magnitude of the pressure, not on the rate of decompression. It seems to occur only at high temperatures, although the temperatures are less than those known to cause sterilisation at atmospheric pressures. It seems therefore that this phenomenon of high speed decompression is unlikely to be related to the cell rupture that occurs in a high-pressure homogeniser. It follows also that it is unlikely that Brookman's [2] hypothesis that cell rupture is caused by rapid decompression is true. It has been rejected by Engler [3] and Doulah et al [4].

However the same hypothesis seems to have been adopted, more recently, by the approach followed by Kleinig and Middelberg [20] in 1996 and subsequently by Kelly et al [17] in 2002. The reason for this is empirical evidence: there is a better correlation between the extent of cell rupture (measured by protein released) and the maximum pressure gradient than there is between cell rupture and operational pressure. However this observed improvement in correlation cannot be attributed to pressure gradients above all other parameters. The same improvement in correlation would be observed by comparing cell rupture with the reciprocal of the gap distance cubed, or comparing cell rupture with the fluid velocity in the gap cubed.

Kelly's work attempts to establish that there must be a number of different mechanisms of cell rupture, each of which is likely to be more dominant depending on the values of various parameters such as impact distance and fluid viscosity. However it does not establish that one of these mechanisms is influenced directly by high pressure gradients which develop in the homogeniser. It merely indicates that higher amounts of cell rupture are more likely to occur if the conditions in the homogeniser are such that higher pressure gradients are also likely to be produced. Both effects could be the result of smaller gap sizes or higher fluid velocities or some other factors. 


\subsection{Turbulence}

Doulah et al [4] hypothesised that turbulence had the greatest influence on disruption in a homogeniser. Using this hypothesis, there was success in obtaining a mathematical expression predicting the protein release which gave estimates similar to experimental results. The turbulence produced in a homogeniser consists totally of random effects and there is no dominating frequency of oscillation. The equipment therefore must work in a different way from other disruptors which use ultrasonic energy at a specific frequency and other equipment which utilise vibration tuned to cause intense resonance at a highly specific frequency which can cause cell breakage of a highly specific size range.

According to Doulah, if the energy of turbulence is high enough, it can exceed the minimum energy required to break the cell wall and thus, disruption could occur. At the time, Doulah stated that both the turbulence characteristics in the homogeniser, and the physical properties of the system such as the cell wall breaking stress were unknown. In the hypothesis, the cells were considered to be the same as liquid droplets and the cell wall was thought to be equivalent to a high surface tension. More recently, these experimental factors have been measured. The turbulence characteristics can be estimated using computational fluid dynamics, and the cell wall breaking stress has been estimated from bond breaking forces of the order $6 \times 10^{-5}$ dynes $(6$ $\mathrm{x} 10^{-10} \mathrm{~N}$ ) based on testing of cellulosic fibres. Because of this, Doulah's hypothesis was rejected by Engler and Robinson [3] using experimental results with yeast. It was found that turbulent eddies did not have sufficient energy for cell disruption.

In the case of liquid droplets, fragmentation will occur when the energy associated with an eddy of the right size exceeds the surface energy of the droplet. With a microbial cell, the situation is more complex. Even if a single encounter with a violent eddy causes the bond between various molecular chains in the cell wall to be broken (the bonds being hydrogen bonding and Van der Walls forces), that would not by itself cause complete fragmentation of the whole cell wall. There would also have to follow a process of pulling and twisting to allow one molecular chain to be gradually pulled away from its neighbours, and then similar activity with many other molecular chains until the cell wall could be said to be disintegrated. (There is evidence that glucan molecules in the yeast cell wall are arranged in triple helices.) While experimental evidence indicates that there is not sufficient energy to cause the initial bond to be broken between these molecules, it is probable that turbulence plays an important role in supplying the energy for the subsequent, gradual, pulling apart of a molecular chain from its neighbours, once the initial bond has been broken.

However if turbulence is to be a significant cause of disruption or breakage of cells, then high temperature and high energy intensities are required. The same argument of insufficient intensity could also be applied to the principle of using ultrasonic energy inputs within the homogeniser. Tuned vibration would also be ineffective as one frequency can only break cells of a highly specific size range. Since any collection of cells passing through the equipment will be composed of cells with different diameters, this method would also be ineffective.

According to Walstra and Smoulders [16] turbulent flow is more likely if there is a large flow rate as found in a large scale homogenisation operation. However although the turbulence may be more widespread, it does not follow that the energy density of the turbulent eddies will be greater, and therefore turbulence is not more likely to cause cell rupture in larger equipment. 


\section{$\underline{2.3 \text { Cavitation }}$}

An explanation of the process of cavitation was provided by Brennen [21]. When the pressure in a pure liquid decreases below the vapour pressure of the liquid, at a given temperature, there is a tendency for bubbles of vapour to form on favourable nucleation sites such as irregularities on a surface. As will be later described, when the pressure is increased again, the bubbles will collapse. According to Balasundaram [22], it is during this bubble collapsing phenomenon that conditions are generated which would allow cell wall breakage to occur, and therefore cavitation could be a mechanism for cell wall rupture. Gas cavities collapse when the pressure downstream of the gap recovers.

The collapse of such bubbles can be studied more easily if it is assumed that the bubble has become detached from the surface irregularity (as is often the case) and is flowing freely in the liquid before the external pressure is increased. The bubble will often be spherical.

The size of the bubble is governed by a balance of forces. The force tending to make the bubble larger is the pressure inside the bubble which, being the vapour pressure, is higher than the pressure in the surrounding fluid, and the force opposing this is the surface tension of the liquid. When the external pressure in the surrounding liquid is increased, there is a change in the balance of forces, and the pressure inside the bubble is no longer so much greater than the pressure in the surrounding liquid, so that the force tending to make the bubble larger is reduced. This has the effect of causing the bubble to reduce in size.

It might be thought that a new equilibrium position would be reached in which the forces tending to enlarge the bubble would balance the forces tending to reduce it. However this does not happen. If a gas was trapped inside the bubble, the reduction in its size would cause an increase in the pressure of the gas and so a higher pressure would be created to oppose the surface tension force tending to reduce its size. But this cannot happen inside a bubble containing only the vapour of the liquid. Its pressure is fixed at the vapour pressure which can only change if the temperature changes.

The result therefore is that the bubble continues to reduce in size, and as it does so, the surface tension force becomes stronger in comparison to the difference in pressure between the inside and the outside of the bubble. Therefore the rate of reduction in size becomes greater as the bubble becomes smaller, and so the bubble diminishes and finally collapses completely.

The violent collapse of bubbles explains why the phenomenon of cavitation can produce such unusual results. Although the volume of the collapsing bubble is very small, the forces causing the collapse build up to such high values that the density of the energy produced is very large. It is estimated that temperatures of around 40,000 times ambient temperature can be reached [21]. This is sufficient to form free chemical OH- (hydroxyl) radicals, and explains why the iodide ion is converted first into an iodine radical and then into molecular iodine [23]. The estimation of the effects of cavitation was carried by Shirgaonkar et al [13] was based on the measurement of liberated iodine by $\mathrm{OH}$ - free radicals. This measurement appears to assume the liberation of iodine from a mechanism similar to cell breakage and not from the temperature from the cavity collapse. 
It is quite difficult to produce a liquid which has no dissolved gases in it; it is much more normal for a certain amount of gas to be present also. Henry's law states that the solubility of a gas is proportional to the pressure in the liquid. Therefore as the external pressure in a liquid is decreased, the solubility of the gas decreases also, and so gas bubbles often become apparent and noticeable in liquids under reduced pressure. When the external pressure is increased again afterwards, the bubbles grow smaller, but in this case there will be a gas trapped inside the bubble, so that the pressure inside the bubble will increase as it collapses and this will tend to slow down the collapse.

Therefore when dissolved gases are present, a phenomenon similar to cavitation takes place, but the violence of the bubble collapse is reduced, and if there are large quantities of dissolved gases present, the cavitation-like phenomenon produces much more gentle and gradual reductions in bubble size.

Even when small amounts of dissolved gases are present, serious damage can be done by cavitation-like phenomena to equipment such as ship propellers, pumps and turbo machinery. However, it is most unlikely that suspensions of living microbes will occur in environments where there are only small amounts of gases present, as explained in the next paragraph, and therefore it is most unlikely that this cavitation-like phenomenon can be the cause of cell rupture.

The metabolism of unicellular organisms may involve aerobic respiration which depends on dissolved gases being present in the surrounding fluid. Even when the metabolism involves anaerobic reactions, one of the end products is always carbon dioxide which must be released into the surrounding liquid in dissolved form. Therefore one must expect large quantities of dissolved gases to be present whenever there is a suspension of living microbes. The amount of dissolved gases can often be assessed by observing the nature of the cell suspension after homogenisation. This is because the dissolved protein acts as a surface active agent and stabilises the bubbles once formed such that a stable froth is often produced.

The greater the amount of dissolved gases are present, the less violent will be the cavitation-like phenomenon, and it seems likely that a suspension of living unicellular organisms will have large quantities of dissolved gases in the surrounding liquid. It seems therefore unlikely that cavitation-like phenomenon could be sufficiently violent to cause cell rupture unless the surrounding liquid has undergone some treatment to remove dissolved gases, for instance, by increasing the $\mathrm{pH}$ to a very high value. In true cavitation, there are no dissolved gases present.

In view of this, it is strange that cavitation is so often suggested as an explanation for cell rupture in homogenisation. The cavitation inception number [14] is defined in terms of the vapour pressure of pure water and while it might be legitimately applied to different experimental arrangements [24], it is also applied to cell rupture work despite the fact that the bubbles observed in regions of low pressure must consist almost entirely of dissolved gases.

The remarks of Phipps [18] [7] about cavitation in a homogeniser were given in context of studies of oil droplet breakup and not for cell rupture. He stated that cavitation and separation flow effects are more likely to be found for square edge valve seats than rounded valve seats as in Figure 7. Also the existence and extent of cavitation has been determined empirically by measuring the amount of iodine which has converted from dissolved potassium iodide [13] as a 
solution was passed through a homogeniser. However this can only be applicable for cell rupture analysis if steps are taken to exclude dissolved gases in microbial suspensions.

Because of the existence of large quantities of dissolved gases in cell suspensions in most of the studies of cell rupture, it would seem appropriate to modify the computational fluid dynamics model to allow for special effects which occur once the external pressure falls below atmospheric. Under the circumstances of external pressure decreasing to a value below atmospheric, as stated previously, gas bubbles will begin to appear, and they will then appear in such quantities that the flow characteristics are altered radically. Under conditions where the pressure remains above atmospheric, the continuity equation can be simplified to predict that there will be no change in the fluid density and that the fluid is incompressible. But when this is not true, when the pressure falls below atmospheric pressure, large numbers of gas bubbles will develop in fluids with quantities of microbial cell suspensions, and under these circumstances the average fluid density changes and the fluid becomes compressible. Because of this, it is most unlikely that the pressure can fall to values approaching the vapour pressure of water.

\subsection{Wall Impact and Impingement}

In his analysis, Kelly [10] considered the case of cell breakage in a homogeniser taking place at low operating pressure in liquids of low viscosity. He argued that the mechanisms of turbulence, pressure gradients and shear stresses (not yet described) could not be the cause of cell breakage because his analysis predicted that no breakage should occur under these conditions. However cell breakage was observed under these conditions and Kelly attributed it to impingement, which, he believed, could occur when the impact distance was small. The impact distance is the distance between the outside surface of the valve rod and the inner surface of the impact ring. The smallest impact distance Kelly used was $0.15 \mathrm{~mm}$ in his study. [10]

It had been proposed already by Kesharvarz-Moore et al [15] that impingement and impact are the two main causes of cell disruption in a high-pressure homogeniser. As normally understood, impact is the collision of two objects (for instance, a cell and the impact ring), whereas impingement is a special case of impact in which one object (for instance, the impact ring) is eroded gradually by large numbers of small impacts caused by numerous discrete solid objects (cells or solid impurities) flowing in the liquid at high velocity.

Kelly's empirical formula (Eqn.1) attempts to predict the fraction of cells broken by impingement using values of the impact ring pressure, as follows [17] [10]:

$f_{f}=\left\{\begin{array}{cc}0 & P_{r} \leq 160 \\ 0.01 P_{r}-1.6 & 160 \leq P_{r} \leq 240 \\ 0.8 & P_{r}>240\end{array}\right\}$

The impact ring pressure is the value of pressure at the wall of the impact ring where impingement and stagnation are most likely to occur (marked $\mathrm{x}$ in Figure 6 (c)). In the homogeniser studied by Kelly [17], when any other impact rings were used, the impact ring 
pressure became too low to allow cell breakage. This does not seem to be the case with the homogeniser used by Floury et al [5]. However, the geometrical arrangement of the homogeniser valve parts in both these cases [17] [5] is different from the arrangement in the homogeniser used in this study.

The word "impact" suggests that the mechanism must be related to the fracture of brittle solids which occurs during a collision. In that case a compressive pulse is generated and passes through the solid. The actual fracture depends on the existence of flaws in the structure of the solid, and when a flaw exists with an orientation of 30 degrees to the direction of the pulse, a tensile stress is produced in the solid which may be sufficient to cause fracture.

However there are a number of critical differences between the classical description of impact as a mechanism for fracture of brittle solids, and the rupture of the cell walls occurring in a high pressure homogenizer. The most obvious of these is that the cell wall is composed mainly of soft materials which can absorb strong compressive pulses without fracture. The cells probably resemble a tennis ball more closely than a delicate item of glassware. There may be some sections of the cell wall which are composed of crystalline materials which may be brittle, and other sections such as bud scars are known to contain high proportions of chitin which can be brittle. However these sections are considered to be very small components in the cell wall and, because most of the other parts are easily deformed, strong compressive pulses would be attenuated over very short distances. Therefore the probability of fracture by impact is very small.

The other major difference is that any collisions (if any collisions occur at all) take place in a water environment in the normal operation of a high pressure homogenizer whereas in the fracture of brittle solids the collisions almost always take place in air or a gaseous environment. Water differs from air in being almost incompressible and in having a much higher viscosity. The result is that much more energy is required to allow solid objects to move in water at a velocity which is different from the surrounding water. When a solid body is moving through water, because of the incompressibility, water must be removed from a position in front of the object and water must be deposited to a position behind the object. There is therefore a need for water to flow along the surface of the object from the front to the back. The high viscosity involved in this flow causes a continuous drag on the object, making it very difficult to allow high velocity differences between water and free objects suspended in it, to continue over a significant distance. On the other hand in air, objects can maintain their velocities relative to the air over long distances.

A related effect occurs when two objects move at high speed towards each other with the potential of a violent collision. Again, because of its incompressibility, the water between the two objects must be removed to allow the objects to approach one another. In the case of highly stream-lined objects moving towards one another, there would be very little water to be removed between them. However in the case of a spherical cell approaching the almost flat inner surface of the impact ring, large quantities of water must be removed. In fact, as the objects come within a few nanometres of each other, the velocity of the water between them must be many multiples of the velocity of approach of the objects. Because of this, the water 
provides a "cushioning" effect, as demonstrated in figure 7, which often prevents potential collisions between solid objects, and when collisions occur, they are much less violent.

This does not happen when the potential collision is taking place in air, because air is easily compressed, offering very little resistance to the movement of two objects towards each other.

Despite these considerations it would be wrong to conclude that impact, or impingement, can never be the cause of cell rupture. It is often the case that a groove develops on the inside surface of the impact ring, after operating the equipment over a long time. This might be due to erosion, as a result of the jet of water striking the surface, and if this is true, solid objects in the jet of water must also strike the impact ring with considerable force. The damage might also be due to the occasional occurrence of very hard particles in the water by accident. The impact ring is usually fabricated using a material which has good wear resistance properties, and, except in the case of impact fracture, described above, soft-bodied materials such as cells, will suffer damage much more readily than very hard surfaces.

It is also true that, once a groove has formed, it is likely to cause further cell rupture. Any cell which happens to be on a flow path which causes it to strike the inner surface of the impact ring exactly on the edge of the groove, will be easily cut into two pieces as it collides.

Cell rupture due to collisions with the impact ring cannot therefore be ruled out in all circumstances. The question to ask therefore is whether the rupture by this mechanism is a common event, or a comparatively rare event. The answer to this question depends on whether there are other mechanisms which are more likely to cause the rupture of cell walls in the homogenizer operation.

The radial jet issuing from the gap was investigated using Fluent 6.3.26 for this geometry (see Figure 6). It can be observed that the liquid velocity close to the wall is between 0 and $8 \mathrm{~m} / \mathrm{s}$. The streamlines show that the jet divides into two and follows curved paths, eventually with the fluid moving parallel to the impact ring. If this analysis is correct, the low velocities and the change in direction of the liquid would suggest that wall impact or impingement may not be major causes of cell breakage. If this is the case, it would be more correct to say that the cells graze or abrade off the impact ring. A small number of cells might come into contact with the surface of the impact ring, and if so, an even smaller number might be expected to break upon abrading with it, but a great population of cells are not expected to make contact with the impact ring, especially on one pass through the valve. However the path of a cell flowing through the homogenizer may be quite different from the pathway of the liquid and thus impact may not be so rare.

\subsection{Shear stress}

A number of authors have considered that shear stresses might arise on the surfaces of a cell in the operation of the homogeniser, and if these stresses were large enough they might cause the rupture of the cell wall. However, there are other reports denying shear stress as a cause of 
microbial breakage in a low viscosity suspension such as that encountered with cells in water. Kelly et al [17] [10] and Millar et al [9] concluded that at low viscosity, channel shear stress is an unlikely to cause cell disruption. This conclusion was based the gap size being in the range of 1-11 microns, the viscosity between 1-5 cp (1-5 mPa.s) and the pressure between 2-14 kpsig $(0.138-0.965 \mathrm{MPa})$. These researchers consider channel shear to be the main cause of cell breakage only at high values of viscosity.

Ayazi Shamlou et al [25] analysed the shear stresses which might arise purely as a consequence of turbulence, without taking into consideration any ordered movements of the bulk liquid as it passes through the equipment.

Unless a cell is so small that its movements exactly match the movements of the liquid in a small eddy, there will be some relative motion between the liquid and the cell. If the cell is much larger than the average eddy size, it will be influenced by a number of eddies, and since the velocity of the liquid in each eddy will follow a different, random, pattern, there must be considerable relative movement between the liquid and various sections of the surface of the cell. These relative motions cause shear stresses to develop on sections of the cell wall. It will be appreciated, therefore, that there is a probability that two adjacent eddies swirling in opposite directions will act to produce a section of the cell wall which is in tension, and when the tensile stress is great enough rupture of the cell wall can take place.

Making some assumptions about the violence of the turbulence Ayazi-Shamlou [25] calculated that a tensile force of $540 \mu \mathrm{N}$ could be generated along the cell wall of a $5 \mu \mathrm{m}$ cell in a liquid with density and viscosity similar to water. It was proposed that this is sufficient to cause rupture.

The description above applies only to shear stresses developing purely as a result of the magnitude of the turbulence in the homogenizer operation. However there are a number of other effects which could also produce shear stresses independently.

Because of the high velocities of the liquid through the gap region of the homogenizer, shear stresses must develop on the walls of the valve parts. Various attempts were made to calculate these stresses. Firstly an assumption must be made as to whether the flow is turbulent or laminar. Then, until computational fluid dynamics became available, a further assumption had to be made about the gap size. This provided a value for the average fluid velocity through the gap region. Assuming laminar flow, a parabolic velocity distribution provided values of the velocity gradient close to the walls of the valve parts. In these calculations only the component of the velocity which is parallel to the surface is of interest. The velocity gradient is a measure of this component of the velocity as the point of reference moves from the wall, where it is zero, a short distance into the flow and normal to the surface. The velocity gradient at the wall is the shear rate, and for a Newtonian liquid, the shear stress is obtained by multiplying the shear rate by the liquid viscosity, which is a constant.

This simple geometry can be extended to consider what happens when the surface has an imperfection, such as a protrusion. In this case the fluid must flow around the protrusion, and 
there will be a build-up of pressure upstream of it and a lower pressure down-stream of it. As a result the protrusion will experience a bending moment with a tensile stress on its upstream side and a compressive stress on its downstream side. If the liquid velocity is great enough, the tensile stress will exceed the modulus of rupture of the material, and the protrusion will be broken off. It follows in general that where a liquid moving with a high velocity exerts a high shear stress on a solid surface, any surface imperfections cause a magnification of the stress and this may be sufficient to cause fracture with the result of the removal of the surface imperfection and the creation of a smoother surface.

This description about shear stresses and surface imperfections on valve parts must now be applied to the surfaces of the cells, but in order to do this it is necessary to assess any situations where there is a difference in velocity between the cells and the surrounding fluid, because under these circumstances it is believed that is it most likely that shear stresses may develop so that cell rupture by this mechanism can take place.

A large amount of data has been compiled on the force exerted on a spherical solid body when it is mounted in a fixed position in a tube containing a liquid which is moving horizontally. The data was originally compiled by Lapple and Shepherd [26] who published a table showing the relationship between a coefficient and the Reynolds Number, and it has recently been reduced to a set of equations in Perry's Chemical Engineers Handbook [27]. Strictly speaking the data refers to steady state conditions where the velocity profile does not change across a crosssectional area many times greater than the exposed cross-sectional area of the spherical solid. Therefore the data can only be applied approximately to the region of the gap in the homogenizer where neither of these conditions is true. It is also much more complicated to use computational fluid dynamics because there are two solids, the stationary valve parts and the accelerating cells. However by making a number of assumptions, the data can be applied to give approximate indications of the forces on the cell. One of these assumptions is that the forces acting on the cell depend on the relative velocity between the cell and the liquid. Put more simply, it does not matter whether the solid is stationary and the fluid is moving, or the solid is moving and the fluid is stationary, the solid will experience the same magnitude of force. Another assumption is that the concentration of cells is sufficiently small that the flow around one cell does not have an effect on the flow around the neighbouring cells. If the solid is stationary the forces will cause it to accelerate so that its velocity increases and so that eventually it approaches the velocity of the liquid. Further, if the dimensions of the solid sphere (the cell) are known and an assumption is made that its density is 1.1 times that of water, its mass can be calculated. In this way the magnitude of the forces estimated using the data of Lapple and Shepherd [26] can be used to estimate the acceleration of the cell as it passes through the homogenizer, based on data on the changes in velocity of the liquid as it passes through the homogenizer also.

The velocity of the liquid through the homogenizer can be calculated from the changes in crosssectional area of the flow path. In the entrance section the flow is very slow, but as the liquid approaches the gap, the cross-sectional area decreases in the convergent section and the velocity increases. Because these surfaces on the homogenizer valve studied are flat, the area of crosssection decreases linearly, but the velocity is related to the reciprocal of the area, and as the gap is approached, the velocity follows a hyperbolic curve, increasing at a very high rate. 
This data can be used to estimate the changes of velocity of cells in the flow. In the early stages of the entrance section, it is found that their velocity is quite close to that of the liquid, with a lag of less than $5 \%$. However as the gap is approached, the sudden increase in liquid velocity causes the cells to lag far behind. As they enter the gap region, their velocity is only about half that of the liquid. This causes the cells to accelerate violently, and eventually their velocity approaches the velocity of the liquid in the gap region.

The analysis shows therefore that there are indeed grounds for estimating a large difference in velocity between the cells and the surrounding fluid at the beginning of the gap region. Therefore it follows that there is the possibility of high shear stresses occurring on the surfaces of the cells in this region.

Three further factors need to be taken into account at this point.

Firstly the surfaces of the cell are unlikely to be smooth. The cell wall is understood to have a fibrous structure, being composed of an arrangement of micro-fibrils of carbohydrate polymers wound together. It is expected that various branching members in these molecular chains will allow minute hair-like structures to protrude outwards beyond the cell wall into the surrounding liquid. A cell wall structure like this would be very vulnerable to fracture caused by high shear stresses.

Secondly the cells of cells are not rigid structures, but are believed to resemble very small bags of fluid. Most of the mass of the cell is located in the central cytoplasmic liquid section, while the walls are comparatively thin. For purposes of description the cell can be thought of as composed of two hemispheres joined together. The front hemisphere which has the leading surface is joined to the rear hemisphere which has the trailing surface. The shear stresses, due to the high relative velocity of the surrounding liquid will reach a maximum intensity on the band where the two hemispheres meet. In this situation, the whole of the cell wall which surrounds the rear hemisphere will be under a tensile stress. This is a result of the shear stress along the band forcing the whole cell to accelerate. This is resisted by the mass of the cell, which, because of momentum, exerts a pressure on the rear hemisphere. The tensile stress in the cell wall will reach a maximum at the part of the cell wall which is at the rear of the cell (see $x$ in Figure 7). The whole of the cell wall surrounding this rear hemisphere is under tension, so that if there is a weak part, the fracture of the whole cell wall will begin at that point.

Thirdly, outside the front hemisphere the liquid forms a number of vortices which are shed at regular intervals. The frequency of shedding depends on the relative velocity between the liquid and the solid, and it is very high when the cell is entering the gap region. A number of vortices are shed each time a cell passes through this region. The result of this is that the cell will experience violent recoil as the shed vortex accelerates away. The tensile stress, which is established in the cell wall around the rear hemisphere, therefore does not build up gradually and then decrease gradually. It is applied as a series of jolts as a result of the vortex shedding. 
Finally in this description of possible mechanisms of fracture, attention needs to be drawn to the fact that shear stresses can occur in a homogenizer, not only in the region at the entrance to the gap, as the fluid accelerates, but also in other parts of the equipment. At least two other situations should be mentioned.

There is firstly the region at the far end of the gap where a jet of liquid enters a much wider volume of liquid at the exit region which is almost stationary, close to the inner surface of the "impact" ring. In this region the liquid in the jet decelerates rapidly and seems to divide into two streams with slightly curved pathways (see figure 5). It is expected that cells within that jet stream will also decelerate abruptly, but the analysis carried out during the acceleration stage using the data of Lapple and Shepherd [26] would suggest that there is a lag in the deceleration also. In addition to this, the momentum possessed by the cells as they exit from the gap will cause them to follow slightly different flow paths in comparison with most of the liquid. Both of these factors would indicate that the cells will enter a region where there is a large difference in velocity between the cells and the surrounding liquid. This provides another opportunity for shear stresses to form on the surfaces of the cell walls.

It is interesting that the conditions which maximize the opportunity for shear stress to cause cell rupture in this deceleration zone are a short "impact" distance and a high "impact" pressure. It was been observed by many investigators that when these conditions are met there is an increase in cell rupture. However this does not prove that impact is a valid mechanism of fracture of the cell wall, because the same conditions will also maximize shear stresses at this point, and the observed rupture could be attributed to this effect.

Since the shear stress phenomenon depends on the relative velocity between the solid and the surrounding liquid the same set of features will occur whether the liquid is accelerating or decelerating. Therefore in this case also there will be the tensile stress developing in the cell wall, but this time in the front hemisphere. There will also be the vortex shedding phenomenon, and this time the vortices will be shed behind the cell into the stationary liquid. If the cell happens to be subject to rotation due to curvilinear motion on exiting the gap region, the already inflicted damage on the cell wall as depicted in Figure 7 at location " $X$ " could undergo further damage. If this is happens then damage on the cell wall could be extensive across the gap region and exit region.

The other situations in the homogenizer where there is the possibility of high relative velocities between the cell surface and the surrounding liquid are also in the outlet or deceleration region. They arise because of the "cushioning" effect of water where there is the potential for a violent collision to take place between two solid objects which are approaching each other. As explained in a previous section, because the water is an almost incompressible fluid, there is a need for the water between the two approaching objects to flow away from their paths. If the two objects were highly streamlined, the amount of water to be removed would be small and this would be a minor effect. However this is not the case in the homogenizer: one object is the inner surface of the impact ring, and on a micron scale this is almost flat. The other object is a cell which probably has an ellipsoidal shape. As the two objects come so close to each other that the distance between them is less than a micron, the velocity of the water which must flow away from between them will be a multiple of the velocity of approach of the objects. 
It is still not certain whether collisions take place in a homogenizer with sufficient violence to allow impact to be a common mechanism of fracture in cell rupture. If they do, it is suggested that the velocity of approach at impact must be well in excess of $10 \mathrm{~m} / \mathrm{s}$, and if this occurs, then the velocity of the water escaping between them must be roughly a multiple of $10 \mathrm{~m} / \mathrm{s}$. It is also suggested that a velocity of the surrounding water of this magnitude will produce a very significant shear stress on the surface of the cell.

\section{Conclusion}

Table 2 shows a summary of all the rupture hypotheses and the arguments in support of and against those hypotheses. Rapid decompression must be rejected as a probable cause of cell breakage, a conclusion with support from Engler [3] and Doulah et al [4]. This conclusion has been reached for the following reasons. The deformation of cells by direct pressure would be negligible because of the elastic and compressible properties of cells. Also, results as displayed in figure 3 and 4 show that the rate of decompression slows down as atmospheric pressure is approached. Therefore, there is little chance of a momentum building up causing an overshoot effect so that the cell could be placed in tension. Also, if cell rupture occurred because of rapid decompression, there would be a requirement to maintain the cells at high pressure with the release of pressure only occurring after one hour. However, one homogeniser pass can be completed in a few seconds. Finally, temperatures approaching values required for sterilisation do not normally occur in homogenisation to break the cells.

Turbulence must also be rejected as a major contributing mechanism to cell rupture, for two reasons. Firstly the energy intensity of the turbulence, which occurs in the homogeniser, is not high enough to cause the rupture of the bonds holding the ingredients of the cell wall together. Secondly, although it is possible that turbulence might result in various structures resonating at specific frequencies, and under such circumstances cell rupture could occur, these effects would only be successful for cells of a very specific size. However any natural cell population is composed of individual cells with different sizes, and so this effect cannot be the cause of cell rupture on a major scale.

In addition, cavitation also seems unlikely to play a major role in cell wall breakage in the homogeniser due to the fact that there are significant amounts of dissolved gases present. Dissolved gases would need to be reduced towards a level of what would be found with pure water. Thus with a scale of process in the order of microns to millimetres in the valve region (cavitation induced damage as seen in propellers is with cavitation regions on a much larger scale) as well as the smooth machined surface due to the precise manufacture of valve components, the authors do not envisage a great likelihood of rupture of unicellular organisms by cavitation.

The results of computer simulations presented in figure 6 indicate that the velocity of the fluid is low in the region close to the inner surface of the impact ring. While this result is only true for the particular homogeniser valve dimensions and geometry studied, it seems unlikely that large numbers of microbial cells strike the impact ring with sufficient violence to cause fracture by 
impact. Even if some cells make contact with the impact ring with an appropriate angle to cause a violent collision, it is important to consider the "cushioning effect" of an incompressible fluid, which would reduce the violence of the impact. It is therefore concluded that, impact should not be considered as a dominant mechanism in cell rupture.

Finally, it was concluded that fluid shear stress is the most influential cause of cell breakage by the authors. It can be accepted that there will be a lag of velocity in the gap region for the cells in comparison to the fluid. As fluid velocities should exceed $100 \mathrm{~m} / \mathrm{s}$ for gaps sizes typically used in operation (usually less than $20 \mu \mathrm{m}$ ), this velocity difference should be significant enough to encourage cell wall breakage. Inert characteristics should as wall surface irregularities, protrusions, hair-like components and weak points of the "hemisphere" fusions in a unicellular organism also further strengthen this argument. Breakage of the cellular component in vicinity to the walls of the valve parts either by shear or direct collision as well as tearing by vortex shedding on weak points could also be characterised under breakage by shear. Conditions for breakage by shear are not dependant on scale of process or specific intensities of its characteristic to cover only limited populations of unicellular organisms.

Table 2: Summery of Rupture Hypothesis

\begin{tabular}{|c|c|c|}
\hline $\begin{array}{l}\text { Hypothesis of } \\
\text { rupture }\end{array}$ & In support of hypothesis & Against hypothesis \\
\hline $\begin{array}{l}\text { High pressure } \\
\text { gradient }\end{array}$ & $\begin{array}{l}\text { "Overshoot" effect of expanding } \\
\text { cell wall against terminated } \\
\text { decompression in the exit region } \\
\text { if decompression of fluid mixture } \\
\text { is fast enough when leaving gap. }\end{array}$ & $\begin{array}{l}\text { More recent research finds water like } \\
\text { compressibility of cell walls sufficient } \\
\text { to withstand this effect; results in paper } \\
\text { find the rate of decompression to be less } \\
\text { than } 1.6 \mathrm{MPa} / \mathrm{s} \text {; similar results reported } \\
\text { [20] } \\
\text { Homogeniser pass too short in duration } \\
\text { to allow migration of dissolved gases } \\
\text { through cell wall } \\
\text { Temperature rise by this effect not } \\
\text { sufficient to cause sterilization effect as } \\
\text { noted by Lenihan [19] } \\
\text { Lack of direct correlation of rupture and } \\
\text { high pressure gradients in more recent } \\
\text { works [17], [20] }\end{array}$ \\
\hline Turbulence & $\begin{array}{l}\text { Geometry of exit region in } \\
\text { homogeniser valve makes it } \\
\text { possible for eddies to form. }\end{array}$ & $\begin{array}{l}\text { Cells walls and droplet boundaries do } \\
\text { not have the same tensile strength (this } \\
\text { was assumed in this hypothesis). } \\
\text { Very high energy density eddies and } \\
\text { temperatures required. Lack of evidence } \\
\text { of significant enough increase with }\end{array}$ \\
\hline
\end{tabular}




\begin{tabular}{|c|c|c|}
\hline & & larger scale of process. \\
\hline Cavitation & $\begin{array}{l}\text { Curvilinear motion of fluid } \\
\text { leaving gap and stagnant region } \\
\text { just downstream of the gap along } \\
\text { the curved wall of the valve head } \\
\text { of the homogeniser valve. }\end{array}$ & 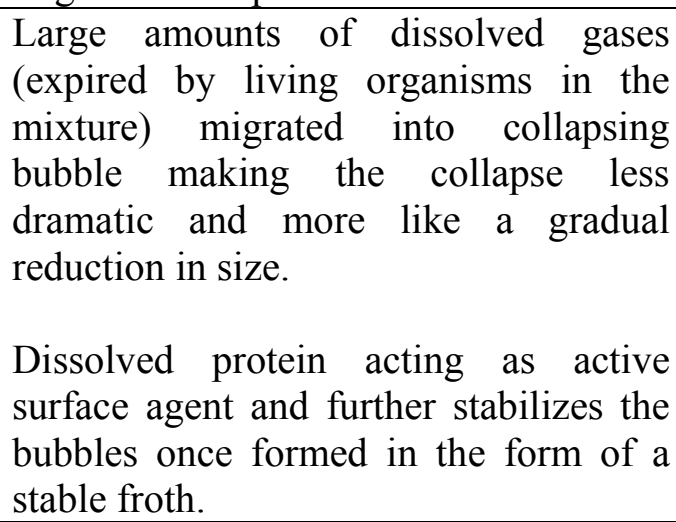 \\
\hline Process scale & $\begin{array}{l}\text { Turbulence may be more } \\
\text { widespread }\end{array}$ & $\begin{array}{l}\text { It does not follow that the energy } \\
\text { density of the turbulent eddies will be } \\
\text { greater, and therefore turbulence is not } \\
\text { more likely to cause cell rupture in } \\
\text { larger equipment. }\end{array}$ \\
\hline $\begin{array}{l}\text { Wall impact / } \\
\text { impingement }\end{array}$ & $\begin{array}{l}\text { High radial jet in gap. Impact } \\
\text { anticipated by previous authors } \\
\text { particularly if the impact distance } \\
\text { (radial distance from gap exit to } \\
\text { impact ring inner surface) is } \\
\text { small. } \\
\text { Surface irregularities or grooves } \\
\text { formed in older impact rings } \\
\text { could increase changes of cell } \\
\text { wall rupture by impact greatly. }\end{array}$ & $\begin{array}{l}\text { Cell walls are not brittle but mainly } \\
\text { elastic and compressible Brittle } \\
\text { components of the cell wall are } \\
\text { insignificant in comparison to the } \\
\text { elastic compressible components. } \\
\text { Compressible pulses are easily } \\
\text { suppressed by the dominant component. } \\
\text { Solid body of cell moves in water } \\
\text { environment where water serves as an } \\
\text { impact buffer just before impact. }\end{array}$ \\
\hline $\begin{array}{l}\text { Wall impact / } \\
\text { impingement } \\
\text { contd. }\end{array}$ & $\begin{array}{l}\text { Contact of cell and wall by } \\
\text { abrasion possible. } \\
\text { Accidental introduction of hard } \\
\text { particles in mixture (impurities) } \\
\text { also a possibility. }\end{array}$ & $\begin{array}{l}\text { Computer simulations in this paper } \\
\text { found impact velocity to be between } 0 \\
\text { and } 8 \mathrm{~m} / \mathrm{s} \text {. This is believed to be not } \\
\text { significant to cause significant rupture } \\
\text { of cell walls. }\end{array}$ \\
\hline Shear stress & $\begin{array}{l}\text { In general the cells studied are } \\
\text { much larger than the average eddy } \\
\text { size. There will be much relative } \\
\text { motion between the liquid and the } \\
\text { cells; high acceleration in the gap } \\
\text { entry with the cells having } \\
\text { significantly greater inertia than } \\
\text { the moving fluid. This is the first } \\
\text { place the cell is placed under } \\
\text { tension and if cell wall is not } \\
\text { ruptured, it should be weaker for } \\
\text { resistance to other downstream }\end{array}$ & $\begin{array}{l}\text { Very difficult to measure } \\
\text { experimentally these stresses as } \\
\text { these are found generally in free } \\
\text { stream at the places of high } \\
\text { acceleration/deceleration/ speed. }\end{array}$ \\
\hline
\end{tabular}




\begin{tabular}{|c|c|c|}
\hline & $\begin{array}{l}\text { phenomenon. } \\
\text { Deceleration of the fluid and cells } \\
\text { could produce further shear on the } \\
\text { cell wall when leaving the gap. } \\
\text { Possibility of } 2 \text { eddies swirling in } \\
\text { opposite directions in a volatile } \\
\text { manner on the rear hemisphere as } \\
\text { seen in figure } 7 \text {. This could lead } \\
\text { to vortex shedding which could } \\
\text { easily rupture the cell walls. } \\
\text { Surface imperfections } \\
\text { Hollows from joints where the } \\
\text { two hemispheres of the cell meet } \\
\text { as in figure } 7 \text { or minor hair-like } \\
\text { structures on the wall) can cause a } \\
\text { magnification of stress leading to } \\
\text { increase fracture. } \\
\text { possibility of escaping water near } \\
\text { impact ring just before contact } \\
\text { could be sufficiently rapid to tear } \\
\text { the cell wall. }\end{array}$ & \\
\hline $\begin{array}{l}\text { Others } \\
\text { (number of } \\
\text { passes) }\end{array}$ & $\begin{array}{l}\text { Cells expected to be weaker at the } \\
\text { end of each pass }\end{array}$ & $\begin{array}{l}\text { Generally for large scale profitable } \\
\text { production, one cannot use too many } \\
\text { passes of the mixture. }\end{array}$ \\
\hline $\begin{array}{l}\text { Others } \\
\text { (separation) }\end{array}$ & $\begin{array}{l}\text { Radial jet found to separate at gap } \\
\text { exit (figure 6). }\end{array}$ & $\begin{array}{l}\text { Radial jet does not maintain its high } \\
\text { velocity as in the gap and dissipates } \\
\text { greatly before separating (figure } 6 \text { ). }\end{array}$ \\
\hline
\end{tabular}

\section{Acknowledgements}

The authors would like to thank various members of the staff of the School of Mechanical and Manufacturing Engineering at Dublin City University for their contributions to this study. In particular thanks are expressed to Dr. Khaled Benyounis of the Biowell research group, Dr. Aran Rafferty in the Centre for Research on Adaptive Nanostructures and Nanodevices (CRANN) at Trinity College Dublin, and Habibullah A. Chowdhury of Islamic University of Technology, Dhaka, Bangladesh.

\section{Notation:}

$P_{r}:$ Impact ring pressure $(\mathrm{Pa})$

$f_{f}$ : fraction of total broken cells by impact ring pressure to total cells 


\section{References:}

[1] J.S.G., Brookman, "“Mechanism of cell disintegration in a high-pressure homogeniser"," Biotechnol Bioeng, vol. 17, pp. 371-383, 1974.

[2] J.S.G Brookman, "'Further studies on the mechanism of cell disruption by extreme pressure extrusion"," Biotechnol Bioeng, vol. 17, pp. 465-479, 1975.

[3] C., Robinson, C. Engler, "“Disruption of Candida utilis cells in high pressure flow devices"," Biotechnol Bioeng, vol. 23, pp. 765-780, 1981.

[4] M.S., Hammond, T.H., and Brookman, J.S.G Doulah, "A hydrodynamic mechanism for the disintegration of Saccharomyces cerevisiae in an industrial homogeniser," Biotechnol. Bioeng, vol. 17, pp. 845-858, 1975.

[5] J., et al Floury, "“Analysis of a new type of high-pressure of homogeniser Part B. Study of droplet break-up and recoalesence phenomena"," Chem Eng Sci, vol. 59, pp. 1285-1294, , 2004.

[6] et al. Save, "“Use of hydrodynamic cavitation for cell disruption"," Chem eng res des, vol. 55, no. B67, 1994.

[7] L.W., Phipps, J. Dairy Res. , vol. 41, pp. 1-7, 1974a.

[8] Titchner-Hooker N and Ayazi Shamlou P Siddiqi S, "'Simulation of particle size disruption changes occurring during high-pressure disruption of baker's yeast"," Biotechnol Bioeng, vol. 50, pp. 145150, 1996.

[9] J., et al Miller, "“Using a CFD model to understand the fluid dynamics promoting E. Coli breakage in a high-pressure homogeniser"," Biotechnol Prog, vol. 18, pp. 1060-1067, 2002.

[10] W., Muske, K. Kelly, "“Optimal operation of high-pressure homogenisation for intracellular product recovery"," Bioprocess Biosys eng, vol. 27, pp. 25-37, 2004.

[11] J., et al Floury, "“Analysis of a new type of high pressure homogenizer. A study of the flow pattern"," Chem. Eng. Science, vol. 59, pp. 843-853, 2002.

[12] A., et al. Diels, "“High pressure homogenisation as a non-thermal technique for the inactivation of micro-organisms"," Critical reviews in microbiology, vol. 32, No. 4, pp. Pages 201-216, 2006.

[13] I.Z.S., Lothe, R.R., and Pandit, A.B. Shirgaonkar, "Comments on the mechanism of microbial cell disruption in high-pressure and high-speed devices.," Biotechnol. Prog., vol. 14, pp. 657-660., 1998.

[14] S.T.L., and Pandit, A.B., "The disruption of microbial cells by hydrodynamic cavitation", 9th International Biotechnology Symposium, Washington, DC., IN: Harrison, "Diels, A., et al., "High 
pressure homogenisation as a non-thermal technique for the inactivation of micro-organisms", Critical reviews in microbiology, Vol. 32, No. 4, Pages 201-216, 2006.," 1992.

[15] E., et al Keshavarz-Moore, "“Disruption of baker's yeast in a high-pressure homogeniser: New evidence on mechanism"," Enzyme microb technol, vol. 12, pp. 764-770, 1990.

[16] P., Smoulders, P. Walstra, "“Emulsion Formation" ," In: Binks, B (Ed), Modern aspects of emulsion science, pp. 56-98, 1998.

[17] W., et al, Kelly, "“Model-based control of a high pressure homogeniser"," Proceedings of the American control conference anchorage, AK, USA , May 2002.

[18] L.W., Phipps, "'The fragmentation of oil drops in emulsions by a high-pressure homogeniser"," J. Phys. D: Appl. Phys., , vol. 8, 1975.

[19] S., Lenihan. (2004) University College Cork Webpage Archives. [Online]. http://www.ucc.ie/en/DepartmentsCentresandUnits/AMTIreland/Projects/HighPressureProcessing/

[20] A.R., Middleberg, A.P.J., Kleinig, "'The correlation of cell disruption with homogeniser valve pressure gradient determined by computational fluid dynamics"," Chem. Eng. Sci., vol. 51, no. 23, 1996.

[21] C.E., Brennen. (1995) Cavitation and bubble dynamics. [Online]. http://caltechbook.library.caltech.edu/1/5/BUBBOOK.pdf

[22] S.T.L. Harrison, "Disruption of Brewers' Yeast by Hydrodynamic Cavitation: Process Variables and Their Influence on Selective Release", Biotech. Bioeng., Vol. 94, Issue 2, 2006 B. Balasundaram, IN: Save, et al., "Use of hydrodynamic cavitation for large-scale microbial cell disruption", Trans Inst Chem Eng, Vol. 71C, Issue 75, 1997. Pages: 41-48.

[23] T., Kano, E. Kondo, "INT. J. RADIAT. BIOL ," vol. 54, no. 3, pp. 475-486, 1988.

[24] S. T. L. Harrison B. Balasundaram, "'Study of Physical and Biological Factors Involved in the Disruption of E. coli by Hydrodynamic Cavitation"," Biotechnology Progress, vol. Vol. 22, no. 3, pp. Pages 907 - 913, 2008.

[25] P., Siddiqi, S.F., Titchner-Hooker, N.J. Ayazi Shamlou, "A physical model of high-pressure disruption of Baker's yeast cells," Chem. Eng. Sci., vol. 50, no. 9, pp. pp. 1383-1391, 1995.

[26] C.E., Shepherd, C.B., Lapple, "'Calculation of particle trajectories"," Ind. Eng. Chem., pp. 605-617, 1940 .

[27] R.H. Perry and D.W. Green, Perry's Chemical Engineers' Handbook (7th Edition).: McGraw-Hill., 
1997.

[28] John Shaw. (2009, Juin) "NRC wear materials expertise supports MicroSludge(TM) system commercialization". [Online]. http://ifci-iipc.nrc-cnrc.gc.ca/media/success03-microsludge_e.html.

[29] Carlos Echavarri-Erasun. (2005) microlibrary.org. [Online].

http://www.microbelibrary.org/ASMOnly/details.asp?id=1971\&Lang=

[30] L., W., Phipps, "'The fragmentation of oil drops in emulsions by a high-pressure homogeniser"," J. Phys. D: Appl. Phys., vol. 8, 1975.

[31] J., et al. Floury, "'Analysis of a new type of high-pressure of homogeniser Part B. Study of droplet break-up and recoalesence phenomena"," Chem Eng Sci, vol. 59, pp. 1285-1294, 2004.

\section{List of Figures:}



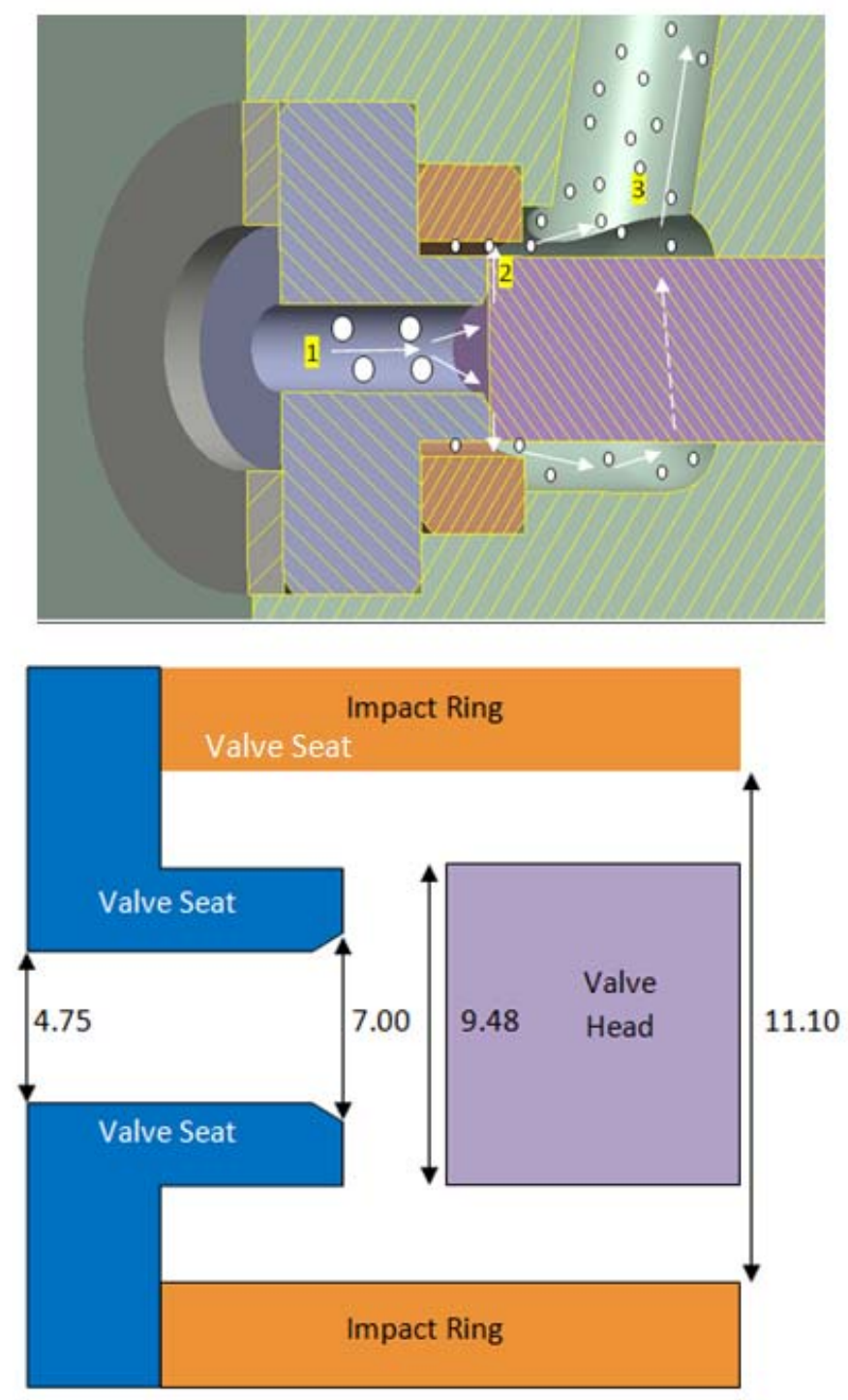

Figure 1: The homogeniser valve region cross section (a) depicting unicellular material breakup with (b) dimensions of valve region used in study 

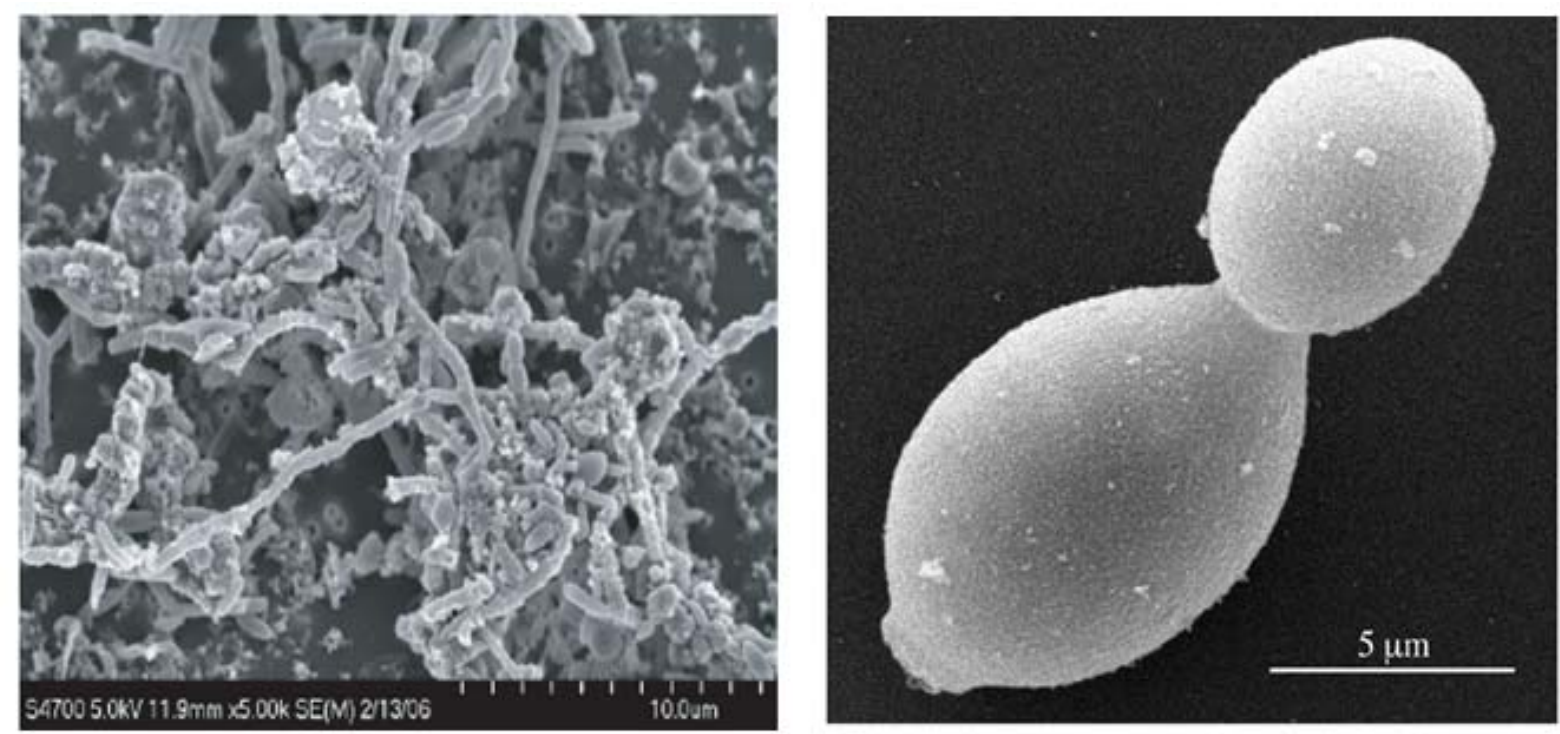

Figure 2: Waste activated sludge microbes [28] with yeast cell multiplying to create single bud [29]

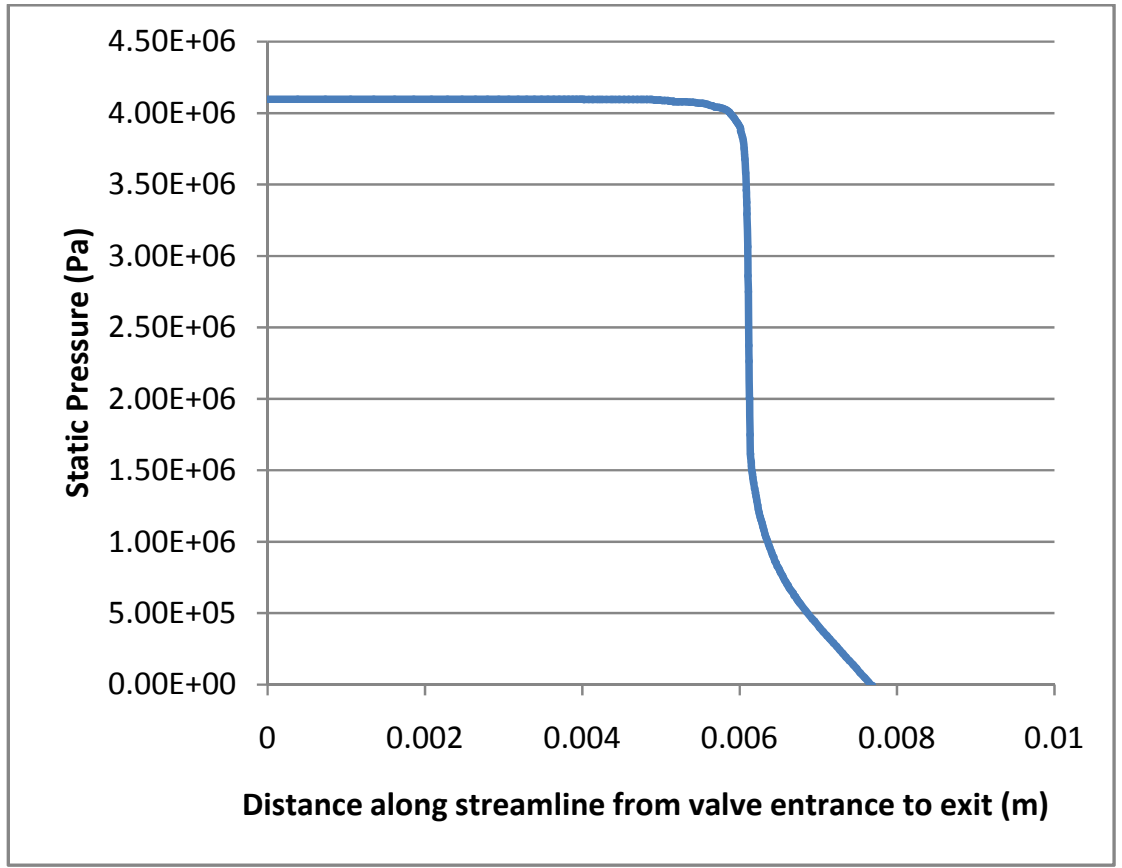

Figure 3: Pressure gradient of liquid passing through the homogeniser valve 

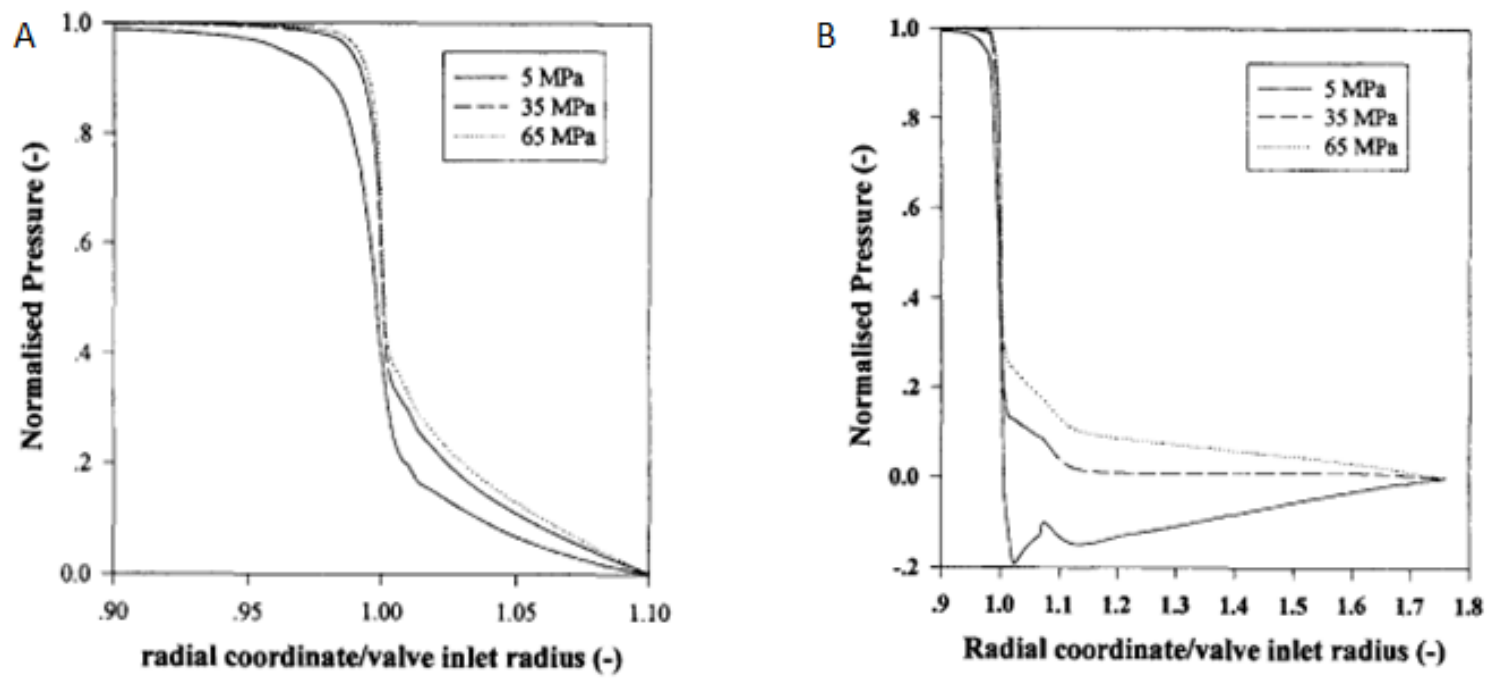

Figure 4: Kleinig`s results [20] of (a) normalised pressure across the centre plane of the valve gap for the rounded valve seat inlet and (b) for the square-edged valve seat at the inlet.
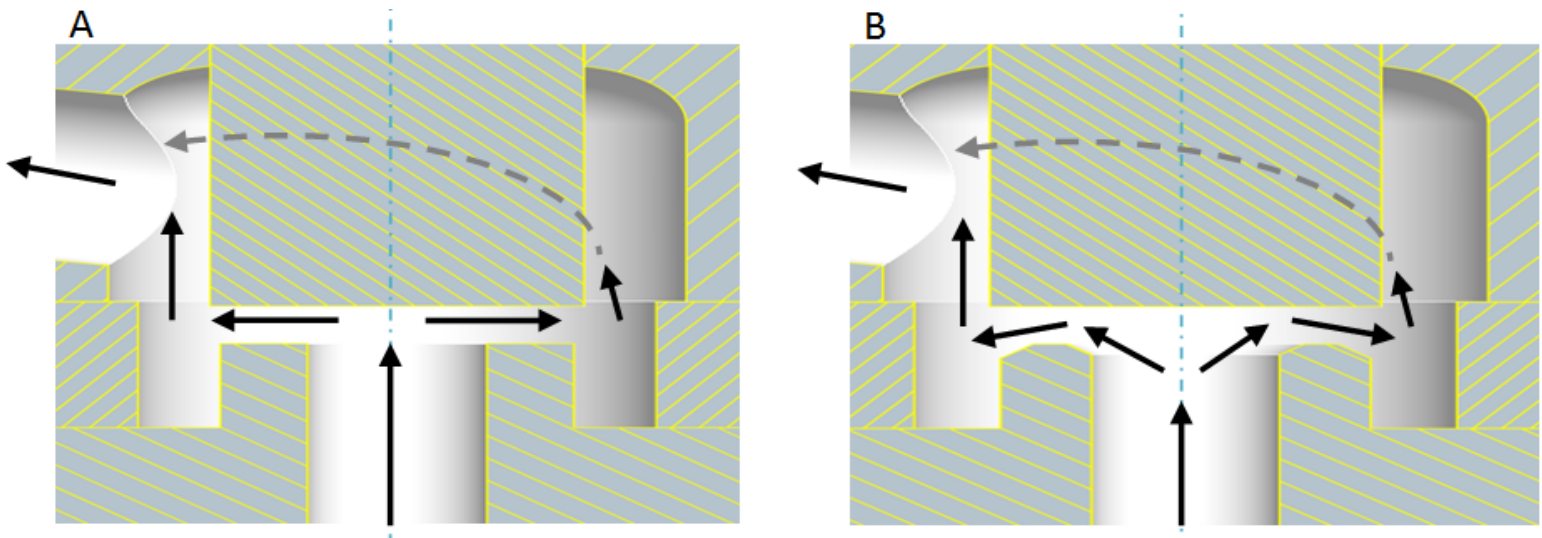

Figure 5: Example of (a) square edged seat and (b) rounded edged seat 


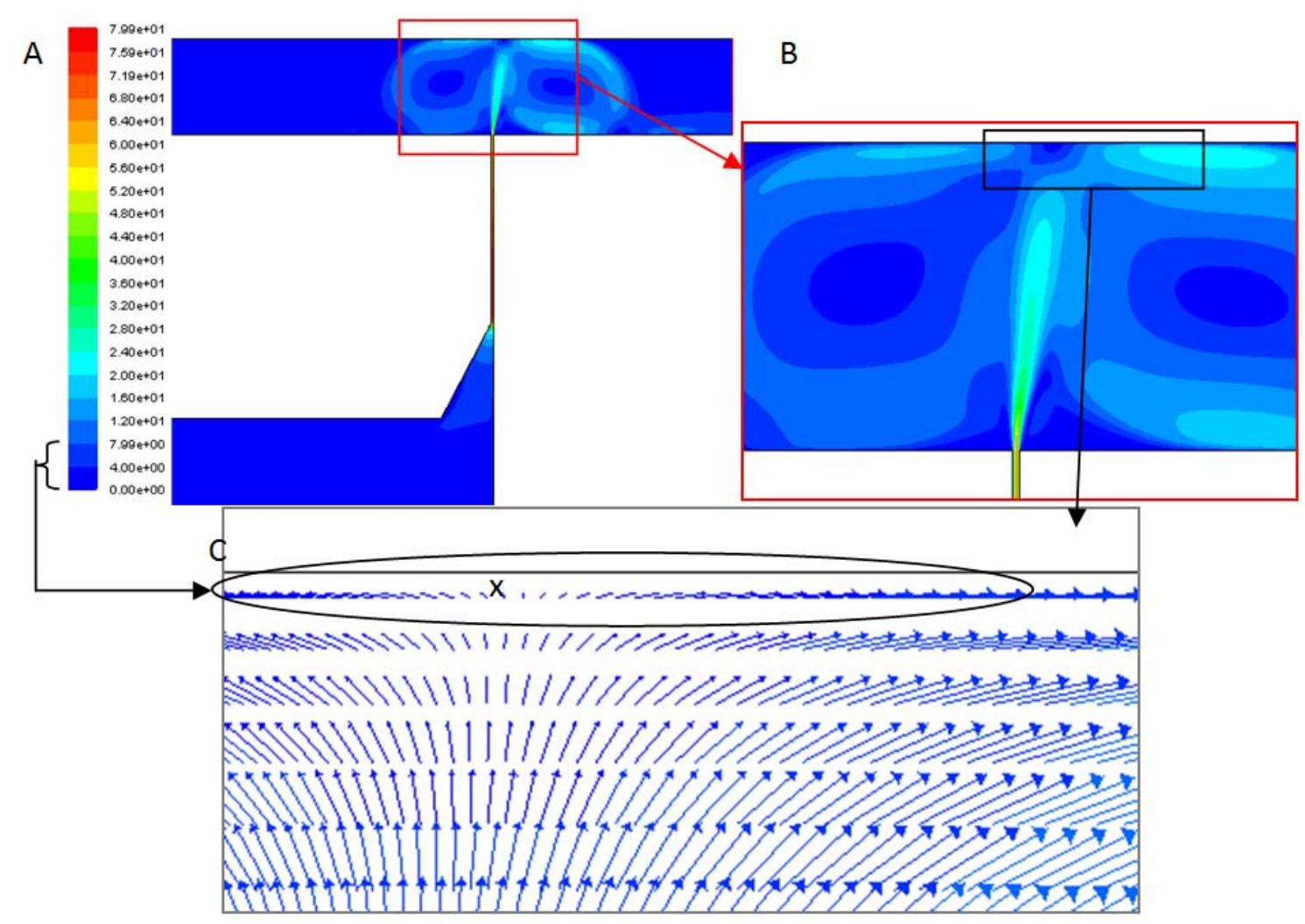

Figure 6: Velocity contours of (a) homogeniser gap and exit region, (b) exit region and (c) velocity vectors at impact ring with small velocity values.

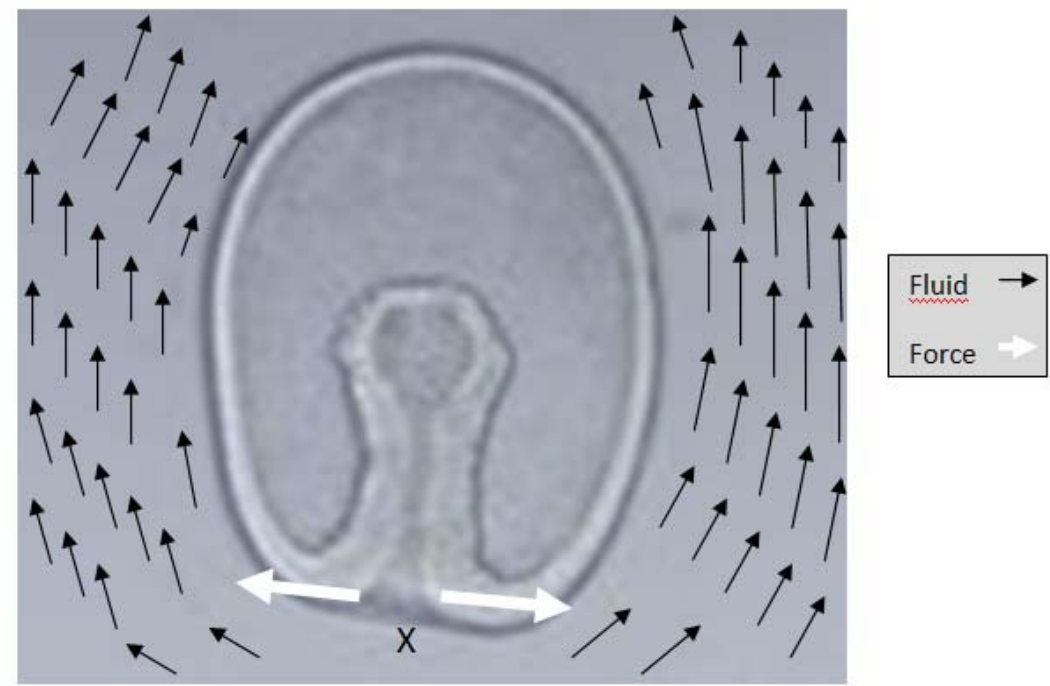

Figure 7. Weak point of a typical cell where two hemispheres meet (black arrows represent fluid flow past cell and white arrows represent force vectors). Note: Not to scale, and the weak point may not always occur at the point of maximum tension. 